Tesis. Año 12, 11(12), 103-118

\title{
Poética del cuento moderno de Flores nocturnas de Miguel Bances
}

\author{
Miguel Luis Bances Gandarillas \\ miguelban@yahoo.es
}

\section{Resumen}

El presente artículo trata de establecer la poética del libro de cuentos Flores nocturnas de Miguel Bances. Se parte de la idea de que el ejercicio intelectual que supone la reflexión de la obra por parte del propio autor debe alejarse de ideas generales y se debe, más bien, complejizar las nociones de relato, personaje y lenguaje. En primer lugar, se propone la reflexión sobre dos paradigmas del cuento moderno (Poe y Chéjov) con el propósito de establecer vínculos con el género del relato. En segundo lugar, se busca la adscripción de los relatos de Flores nocturnas con el cuento epifánico. En tercer lugar, se plantea que el personaje debe ser estudiado en la dimensión crítica que propone la relación sujeto-modernidad. Finalmente, se discute la visión de la realidad a partir de la noción de lenguaje con que opera Flores nocturnas.

Palabras clave: poética, sujeto, modernidad, lenguaje, epifánico, texto, representación.

\begin{abstract}
This article tries to establish the poetics of the story book Flores nocturnas by Miguel Bances. It is based on the idea that the intellectual exercise, which supposes the reflection of the work by the author, should separate from the general ideas and that the story, character and language notions should be considered in a greater depth. Firstly, the reflection on two paradigms of the modern story (Poe and Chéjov) is proposed in order to establish links with the genre of the story. Secondly, the ascription of the stories of Flores Nocturnas with the epiphanic story is sought. Thirdly, it is suggested that the character should be studied from a critical perspective which proposes the subject-modernity relationship. Finally, the view of reality is discussed based on the language notion used in Flores Nocturnas.
\end{abstract}

Keywords: poetics, subject, modernity, language, epiphanic, text, representation. 


\section{Poética del cuento moderno de Flores nocturnas de Miguel Bances}

\section{Introducción}

En un breve ensayo sobre la estructura de los relatos, el escritor José de Piérola plantea la idea de que existen tres tipos de finales en un cuento o una novela: cerrado, abierto y circular. Esta clasificación resulta interesante porque no se restringe a un estilo particular, sino que se abre a una idea más general. Para Piérola, los finales delimitan el mundo ficcional y, sobre todo, reflejan la poética del escritor (entendida esta como la visión del mundo que subyace en la obra literaria). De este modo, tenemos que el final cerrado se asocia con la necesidad de reestablecer el orden en un mundo que parece caótico; el final abierto se relaciona con la idea de que la vida es un proyecto inconcluso sobre cuyo final hay pocas certezas; finalmente, el final circular implicaría una concepción no lineal del tiempo que cuestiona la idea de causalidad.

Estas breves reflexiones tienen algo de pensamiento metonímico, porque en realidad no se refieren solo a los finales, sino al todo que constituye el relato. Por lo tanto, estamos hablando de tipos de relatos cuya poética se advierte con cierta claridad en sus finales. Y aún más: estamos hablando de una poética, es decir de una visión de la realidad instituida por el lenguaje y la estructura de una obra.

Lo interesante, en todo caso, es que estas reflexiones me plantean una simple pero demandante pregunta: ¿Qué tipo de final (entiéndase qué tipo de relato) es el que se observa en mi libro de cuentos Flores nocturnas? En un juego de adscripciones (que realizan tanto críticos como escritores) me inclino por el relato de final abierto. La vida es siempre un proceso sin verdades absolutas o verdades transitorias, donde el significado de las cosas está casi siempre oculto, como un espejo negro. Por supuesto, existe una larga tradición del relato moderno que con diversas denominaciones (relato chejoviano, minimalista, epifánico, etc.) apuntan hacia esa idea. Pero una vez resuelto el juego, una vez admitida la 
ubicación de mis cuentos, una vez situados en un orden clasificatorio, emerge la pregunta inevitable: ¿Es suficiente su incorporación a un determinado tipo de cuento?

La ejecución de mis cuentos estuvo acompañada por reflexiones previas sobre el relato, por ideas generadas a partir de la lectura de autores que, a grandes rasgos, escriben textos donde lo importante nunca se cuenta, donde existe una historia secreta construida con el sobreentendido, con la alusión y el final abierto. Pero tengo la sospecha de que mis cuentos no se ajustan exactamente a esa familia de grandes cuentistas. No, no es suficiente.

\section{Teoría para dummies}

Cualquier escritor de relatos tiene un saber básico: el cuento tiene tres elementos esenciales que se ensamblan en lo que se llama texto narrativo. El primer elemento es la anécdota, la historia que se cuenta. Toda historia está acompañada de personajes; en verdad debemos decir que existen personajes que tienen una historia. Pero tanto la historia como los personajes son entidades que necesitan ser expresadas a través de un estilo (el tipo de lenguaje con que un narrador cuenta la historia de un personaje) y de una estructura (la disposición de la anécdota). Estilo, narrador y estructura forman lo que comúnmente llamamos discurso.

Como hemos señalado anteriormente, la anécdota determina una forma de relato, pues la estructura es abierta o cerrada, clásica o moderna. Los personajes, nos dice la teoría básica, pueden ser planos o redondos; los primeros son funcionales a la trama, los segundos tienen una densidad interna que los vuelve significativos en sí mismos. Finalmente, en cuanto al discurso, sabemos que la cohesión entre estilo y estructura determina ciertas formas de lenguaje (realista, surrealista, fantástico, experimental, etc.).

El mundo de los talleres de narrativa que pululan en nuestra ciudad se ha dado maña para explicar el fenómeno del cuento con estas pocas verdades funcionales. De este modo, la compleja realidad del discurso literario se reduce a lo tecnológico: una suma de enunciados simples sobre el cuento cuya finalidad es un producto aceptable.

Admitiendo que hay un problema de simplificación en esta teoría para dummies, debemos aplicar un enunciado performativo: Al taller hay que añadirle poética, porque escribo-bago textos a partir de unos principios estéticos. En lo que sigue, haré un acercamiento a los dos paradigmas del cuento y posteriormente trataré de establecer una poética de mi libro Flores nocturnas, teniendo en cuenta que se debe complejizar el tipo de relato, el personaje y la relación lenguaje y realidad. 


\section{El paradigma de Poe. El cuento de efecto único}

Aunque el origen del cuento hunde sus raíces en un tiempo muy remoto, a través de formas narrativas breves como la fábula o el apólogo, este género literario, tal como hoy lo conocemos, se fue configurando en Occidente a partir del reconocimiento de un autor individual. En el siglo XIV aparecen tres obras fundamentales: El conde Lucanor de Juan Manuel, el Decamerón de Boccaccio y los Cuentos de Canterbury de Chaucer. Estas obras, además, dan inicio a una serie de rasgos diferenciados de otros tipos de narraciones cortas. Por ejemplo, las marcas de oralidad (frases cortas usadas para narrar anécdotas muy breves y precisas) desaparecen y los personajes empiezan a ser caracterizados con mayor profundidad.

No obstante, el cuento solo adquiere plena autonomía poética, en tanto género independiente, con Edgar Allan Poe. Este autor norteamericano estableció los principios del cuento, que fueron asumidos, debatidos y cuestionados por cuentistas posteriores, pero que constituyen hasta hoy la única vía para distinguir este género más allá del evidente rasgo de la brevedad. Con otras palabras, la importancia de Poe es muy grande, puesto que, por una parte, estableció los límites del cuento en tanto género y, además, fijó las pautas de un tipo de cuento que tradicionalmente se ha dado en llamar cuento de efecto único.

En este tipo de relato que, como hemos señalado, constituye todo un modelo de cuento, predomina una correspondencia muy ajustada entre los elementos del cuento y tiene como propósito lograr un efecto único e impactante en el receptor. Además, la brevedad es un rasgo constitutivo del cuento, pues solo de este modo se puede alcanzar un rasgo más importante: la intensidad.

Según su propia noción romántica, que tan vasta influencia ha tenido en la teoría y la práctica de esta modalidad discursiva, el verdadero cuento tiene que ser relativamente breve por una razón fundamental: debido a esa especie de ley universal de la proporción inversa entre intensidad y extensión, según la cual sólo lo breve puede ser intenso." (Pacheco, p.19).

Desde el punto de vista de Poe, entonces, es necesaria la intensidad para producir el efecto deseado. La intensidad no es, sin embargo, un rasgo epidérmico; es, sobre todo, el sostén estructural de todo cuento. Si lo que se busca, desde la perspectiva de Poe, es el efecto sorpresivo, el efecto único, la intensidad se construye a partir de una composición esquemática, ajustada a un patrón de etapas secuenciales. Con otras palabras, "para que un texto posea valor artístico debe tener una extensión restringida y una minuciosa armonía formal con el propósito de provocar en el lector una emoción unitaria y articulada." (Rest, p.51) 
En la concepción de Poe, en efecto, el receptor cobra una importancia muy grande. La extensión del relato, es decir, su brevedad, apunta a que la atención del lector no decaiga al leer el cuento, con el objetivo de que pueda este tener una impresión rápida y de conjunto. Relacionados también con el lector están la unidad estructural y el efecto sorpresivo, pues todos los elementos y recursos están en función del final, que debe conseguir un efecto impactante, una sensación de misterio.

Para Poe, la idea de efecto único, impactante y ligada a un sentido misterioso, deriva de la tradición romántica y del idealismo filosófico. Desde este punto de vista, el mundo es algo más que aquello que puede ser percibido por los sentidos, la realidad está más allá del mundo de las apariencias. El significado del cuento, el efecto intenso que percibe el lector, está más allá de la superficie del relato, así como en la visión metafísica romántica la realidad está más allá de las apariencias sensibles. (Cf. Pacheco, p.22)

\section{El paradigma de Chéjov. El cuento epifánico}

A fines del siglo XIX, Chéjov y otros cuentistas importantes, como Turgueniev y Gógol, plasmaron en sus obras el malestar social e individual de la vida cotidiana en la Rusia de entonces. A través de narraciones de sucesos minúsculos, daban cuenta de la condición humana, cercada por el desasosiego social y cultural. Con otras palabras, sus relatos, más allá de lo narrado, de manera implícita, nos permiten acceder a sentidos secretos y básicos de la condición humana. Pero sin duda fue Chéjov quien se plasmó con mayor hondura y versatilidad este tipo de cuento que generalmente es llamado, en contraposición con el modelo de Poe, relato de final abierto.

Una diferencia crucial con Poe es que este tipo de relatos dan cuenta efectivamente de la condición humana dentro de un universo marcado por hechos cotidianos, a través de personajes sin ningún valor trascendente. Otra diferencia, de índole estructural, se aprecia en lo siguiente: frente a una estructura de etapas marcadas por secuencias netamente encadenadas por un orden causal, en los relatos abiertos se "exalta el valor narrativo de la escena, del momento, de la atmósfera anímica y vivencial.” (Barrera, p.45).

De este modo, podemos decir que Chéjov otorga dos postulados principales al nuevo modelo de cuento que ha creado. El primero se refiere a la ruptura de una estructura demasiado rígida que, finalmente, obligaba a todos los elementos del relato a someterse a una lógica de causa y efecto. Frente a ello se propone la creación de una atmósfera o de una situación. "La acción ocasional, el estado de ánimo, la pintura incompleta pero sugerente, pueden ser la esencia del cuento, del relato breve, síntesis del acto de contar." (Barrera, p. 45) 
El segundo postulado es la objetividad reflexiva o, dicho de otro modo, la motivación no explicativa. Esta idea también puede ser aplicada a buena parte de la narrativa moderna y consiste en que siempre queda algo no explicado en el cuento porque de lo que se trata es de impresionar al lector y, a partir de esa impresión, este empezará a meditar.

Eileen Baldeshiwiler ha empleado una terminología alternativa a la que estamos usando, pero en esencia apunta a la misma idea. El paradigma de Poe estaría ligado a la narrativa épica, mientras que el modelo de Chéjov a la narrativa lírica. La primera se caracteriza "por una acción externa que se desarrolla de manera silogística, mediante personajes esbozados principalmente para que lleven adelante una trama; culminan con un final decisivo que muchas veces facilita una valoración universal (...)” (Baldeshiwiler, p.167).

En cambio, la narrativa lírica se concentra en cambios internos, estados de ánimo y sentimientos; utiliza una variedad de patrones estructurales que dependen de la forma de la emoción misma; la mayoría de las veces presentan un final abierto y suelen expresarse en el lenguaje condensado, evocador y a menudo figurativo de la poesía" (Baldeshiwiler, p.168)

El paradigma de Chéjov tuvo en el irlandés James Joyce su formulación más depurada y con él podemos emplear plenamente el término de relato epifánico.

\section{Poética y metatexto. El tipo de relato}

E1 libro de cuentos Flores nocturnas presenta una estructura abierta de los relatos, es decir, una organización de la historia que implica una postura contraria al cuento basado en la anécdota. Esta forma ha sido una elección plenamente consciente, pues creo que la no sujeción a la anécdota cuestiona la idea de que debe haber un sentido unívoco y, además, con ello se plantea el problema de la capacidad representativa del lenguaje. Esta estructura del relato ha recibido distintos nombres (cuento de final abierto, relato chejoviano, minimalismo, etc.), pero considero que el más preciso sería el de relato epifánico; por esta razón, abordaré sus rasgos constitutivos.

Un relato epifánico narra acontecimientos triviales cuidadosamente descritos y las implicaciones (el sentido) de la narración nunca quedan del todo claras (Díaz, p.111). Con otras palabras, la historia narrada no tiene un significado nítido, tiene varios posibles, en ese sentido es multiestable. Con esto entramos directamente al problema del sentido: un relato epifánico implica una evolución de lo unívoco a lo abierto.

El relato epifánico se puede ilustrar con uno de mis cuentos. En "Números", una pareja de esposos ha decidido salir un sábado por la noche, pero de pronto 
reciben una llamada telefónica. Un encargado del zoológico les advierte que un animal se ha escapado y que deben permanecer en casa. Solo podrán salir a la calle cuando les avisen que el animal ha sido capturado y haya pasado el peligro. En el transcurso del relato, el lector puede advertir que late un conflicto no resuelto entre ellos, una distancia que se simboliza en el hecho de que ella trabaja con letras y él con números. Al final, otra llamada telefónica le avisa a la esposa que el animal ha sido capturado, pero al ser requerida por su cónyuge, esta le dice que el animal aún no ha sido capturado.

Este final es claramente abierto, pues el lector no sabe a ciencia cierta la razón por la que la esposa da una respuesta contraria a la verdad. En esencia, el lector "sabe" que ha ocurrido "algo importante" en el mundo interior de los personajes, tal vez es una revelación de la profunda soledad y la incomunicación existente entre la pareja. Y todo esto se ejecuta en medio de esa cotidianidad en apariencia banal en la que viven los personajes. Como en muchos cuentos de Raymond Carver, basta con que ocurra un suceso fuera del orden normal de las cosas para que los personajes sufran una transformación. En "Números", además, tanto los personajes como el lector nunca saben del tipo de animal que se ha escapado del zoológico, con lo cual se patentiza una atmósfera de incertidumbre, de sentido no delimitado.

Para un lector agudo, no existe ningún truco en este relato, se constituye, más bien, a partir de ciertos principios estéticos y convenciones literarias. Dicho de otro modo, el relato epifánico es un modelo de cuento que la tradición moderna ha procesado y establecido. Una lista selecta de autores que han trabajado con el relato abierto o epifánico está conformada por Anton Chéjov, James Joyce, Ernest Hemingway, Flannery O’Connor, John Cheever, Richard Ford, Raymond Carver, Tim O’Brien, Kiell Askildsen y Richard Ford. Estos cuentistas comparten un universo estético que está delimitado por principios que la comunidad de lectores ha establecido. Estos principios, que reciben el nombre de metatexto, son "un conjunto de enunciados que formulan los principios generales del hacer al cual el texto pertenece" (Huamán, 2003, p. 24).

\section{Poética II: Personaje, sujeto y crítica}

El personaje es un elemento esencial de la narración no solo porque en él se aprecia la peripecia de la historia, sino, fundamentalmente porque es un portador de ciertas ideas que sobre el ser humano plantea un autor, en buena cuenta se caracteriza por presentar una visión del mundo. Esta visión del mundo que se observa en los personajes de Flores nocturnas está ligada a la emergencia de un sujeto en crisis producido por el proceso de la modernidad.

En principio, es necesario establecer los rasgos constitutivos del sujeto moderno con el propósito de establecer relaciones conceptuales con los personajes 
de los cuentos. Con otras palabras, el concepto de sujeto en crisis me sirve para establecer el sentido y la simbología implícita de los personajes de Flores nocturnas.

Por esta razón propongo la existencia de dos campos de lectura en relación a la modernidad y al sujeto. El primer campo plantea la relación conflictiva entre razón y sujeto en el marco de la modernidad, tomando en cuenta la idea de autonomía o autorrealización que acompaña al concepto de individuo que emerge en la modernidad (Cf. Touraine, 1994). En este campo de lectura, la respuesta artístico-literaria está ligada a la problematización sobre la pérdida de la autonomía del sujeto moderno; en ese sentido la literatura se convierte en un discurso crítico de la modernidad.

Esta pérdida de autonomía adquiere las características de pérdida del sentido desde el punto de vista existencial, que repercute en una inseguridad en el orden de lo ontológico. Muchos de los relatos de Flores nocturnas se adscriben en esa línea de lectura.

El segundo campo de lectura no contrapone necesariamente el binomio razón y sujeto. Más bien se pueden ver como dos discursos convergentes que se anudan y se necesitan. La autonomía del sujeto es necesaria y constitutiva a la sociedad racional moderna, de tal manera que es cuando menos complicado pensar en la existencia de una sociedad moderna sin sujeto autónomo y, sobre todo, racional. Es cierto, por lo demás, que aquí la noción de sujeto es, según Maffesoli, entendible cuando el ser se sustancializa, se vuelve sujeto: individuo, institución, estado nación. La noción de sujeto que estamos describiendo es la del yo moderno instrumental, enajenado del mundo vuelto sustancia.

Pero contra lo cognitivo como idea base del sujeto moderno (sustancialismo) está la idea de la experiencia formadora del individuo, ligada a lo sensible, lo corporal y al sentir: "Hay bumus en lo humano, no solamente lo cognitivo, también un cuerpo, también lo sensible, también olores, humores, instintos" (Maffessoli. p.27)

Los estudios más recientes sobre estética plantean como idea fuerza este aspecto de lo sensible como insoslayable a la noción de lo humano. Por ejemplo, para Terry Eagleton lo estético es por un lado un modelo de la subjetividad humana en la temprana sociedad capitalista y es, por otro lado, "una visión radical de las energías humanas, entendidas como fines en sí mismos, que se torna en el implacable enemigo de todo pensamiento de dominación o instrumental (...)" (Eagleton, p.60). En este caso, Eagleton apuesta por la idea de que lo estético constituye una vuelta creativa a la corporalidad. En nuestro cuento "Los días, el pozo" este nivel del humus aparece subyugado y se representa a través de la metáfora de la depresión. 
Con el propósito de aclarar nuestra propuesta de lectura en relación al sujeto que se observa en los personajes de Flores nocturnas, veamos el siguiente cuadro:

\begin{tabular}{|l|l|l|l|}
\hline campo de lectura 1 & $\begin{array}{l}\text { relación } \\
\text { problemática } \\
\text { entre razón y } \\
\text { sujeto }\end{array}$ & $\begin{array}{l}\text { consecuencia: } \\
\text { pérdida de } \\
\text { autonomía del } \\
\text { sujeto }\end{array}$ & $\begin{array}{l}\text { respuesta artística } \\
\text { moderna (crítica): recuperación } \\
\text { del sujeto /evidencia de la crisis } \\
\text { del sujeto } \\
\text { posmoderna: evidencia de la } \\
\text { disolución del sujeto moderno }\end{array}$ \\
\hline campo de lectura 2 & $\begin{array}{l}\text { relación entre } \\
\text { razón y sujeto }\end{array}$ & $\begin{array}{l}\text { consecuen- } \\
\text { cia: sujeto } \\
\text { sustanciado, } \\
\text { instrumental }\end{array}$ & $\begin{array}{l}\text { respuesta artística } \\
\text { búsqueda de la enteridad: humus } \\
\text { en lo humano }\end{array}$ \\
\hline
\end{tabular}

Aunque es discutible, me parece que hay dos formas (dos poéticas) en que se aborda la crisis del sujeto moderno desde la perspectiva artístico literaria. La primera se despliega en la crítica del sujeto moderno, que ubicamos en el horizonte utópico. La segunda se articula en la idea de que la crisis del sujeto implicaría en realidad una disolución del sujeto y el horizonte cultural en el que se ubica tiene que ver con lo distópico.

Las manifestaciones o correlatos literarios del horizonte utópico o moderno son la novela y la poesía moderna, el discurso de vanguardia, el relato existencial, el cuento fantástico y un grupo de cuentistas que se inscriben en lo que podemos llamar relato epifánico 1 . En este horizonte utópico o moderno, el sujeto se confronta con la sociedad y con los ejes articuladores de la modernidad, lo que desemboca en la crítica del mundo moderno. La novela, por ejemplo, instaura una razón subjetiva donde el personaje se enfrenta a los valores sociales y trata de reivindicar su autonomía en tanto ser. Pero es en el discurso de vanguardia donde se exacerba la estética de lo moderno. Por esta razón quisiera señalar algunos rasgos esenciales de su poética. Esta actúa bajo el supuesto de que el discurso literario no es transparente, de tal manera que en el texto vanguardista se evidencian los mecanismos textuales que producen sentido y, con ello, la autorreferencialidad se convierte en material de la obra. En relación al personaje, el discurso de vanguardia lo entiende como un sujeto en proceso de constitución, lo que revela una crisis del sujeto moderno.

Esta condición del vanguardismo está anclada en el horizonte utópico. E1 vanguardismo es un discurso cuya base es la crítica. La crisis del sujeto es una posibilidad para recuperar al individuo moderno.

¿Y el relato epifánico sobre la base de qué principio construye el personaje? ¿Existe aún un probable elemento de crítica? 
Creo que sí existe una crítica de la sociedad y la cultura pero ya no una crítica de la modernidad. Pienso que los relatos que integran este universo de sentido denominado relato epifánico evidencian un proceso donde los presupuestos de la modernidad se han diluido y con ellos el sujeto que solo puede ser verbalizado en un orden menos convincente.

Evidentemente hay un proceso en lo que va de Joyce y Hemingway (relato epifánico 1) hasta autores como Carver y Ford (relato epifánico 2); en los primeros aún hay sueños por realizar (piénsese en "Eveline" de Joyce o en el cuento "La capital del mundo" de Hemingway), pero en los segundos tenemos personajes inarticulados incapaces de verbalizar su condición que a menudo no parecen comprender del todo. En los relatos, sus vidas parecen deambular en el vacío significativo de lo intrascendente, cuando de pronto se ven sometidas a un momento de inestabilidad (la pérdida de empleo, una ruptura sentimental) que los diluye.

Precisamente la disolución del sujeto o la pérdida de autonomía se puede advertir en mi libro Flores nocturnas. Esta pérdida de autonomía se desprende de una crítica clásica de la modernidad. Me refiero a que la vida contemporánea, la vida de los individuos se ve avasallada por el sistema. Esta idea se puede resumir en la falta o pérdida del sentido de realidad debido a la ausencia de seguridad ontológica (Giddens p.52).

Como señala Giddens, en la modernidad el proyecto del yo se lleva a cabo en un medio social técnicamente competente pero moralmente yermo. En la mayor parte de los procesos globales de planificación de vida "acecha la amenaza de la falta de sentido personal" (Giddens, p.255)

Resulta necesario entender plenamente el significado de la siguiente idea: la crisis de identidad en el sujeto desemboca en inseguridad ontológica. En efecto, cuando decimos que la identidad está en crisis o presenta un problema, el resultado es la falta de sentido personal que está ligado precisamente a la inseguridad ontológica.

Debemos entender que la identidad supone, para el sujeto, una continuidad en el tiempo y en el espacio, un saber quién es, un conocimiento de sí mismo que es el resultado de la interpretación de esa continuidad en el tiempo y en el espacio. Con otras palabras, la identidad es "el yo entendido reflexivamente por la persona en función de su biografía” Giddens (p. 72). De esta manera, la identidad del yo no es un rasgo distintivo que posea un individuo.

E1 mecanismo que ayuda a la identidad es un sistema social: "El individuo experimenta el yo en relación con un mundo de personas y objetos, cognitivamente organizado por medio de la confianza básica, sólo en función de ese 
sistema de seguridad fundamental, origen del sentimiento de seguridad ontológica" (Giddens p. 63)

De tal manera que, el problema en la identidad del sujeto es, concluimos, una inadecuación al sistema, lo que finalmente origina la falta de seguridad ontológica.

Según Giddens, existen tres características del individuo ontológicamente inseguro: (p.73)

1. Falta de sentimiento coherente de continuidad biológica. Esta característica se refiere a que existe una discontinuidad o ruptura en la experiencia temporal. El tiempo se vuelve una serie de momentos discretos, separados, de tal manera que no existe una crónica continua de la vida. Por esta razón, el sujeto puede llegar a angustiarse por la idea de ser borrado o aplastado por acontecimientos que lo afectan desde fuera.

2. La persona, en un medio externo pleno de cambios, se siente obsesivamente preocupada por aprensiones de posibles riesgos que amenazan su existencia y paralizada para la acción práctica. Aquí el individuo presenta una incapacidad para bloquear los peligros que acechan desde el exterior y buscarán fundirse con el entorno para evitar los peligros que la acechan.

3. La persona fracasa en su intento de desarrollar o mantener confianza en su propia integridad. No tiene confianza en su propia integridad; se siente moralmente vacío, pues no tiene una visión amable de sí mismo.

En mi cuento "Flores nocturnas" el personaje-narrador es un hombre que nos cuenta en un principio que su condición económica ha cambiado: se ha vuelto rico. En su nueva casa organiza, junto a su esposa, una reunión para celebrar el acontecimiento. Los preparativos incluyen una cena especial, pero el enorme jardín debe ser arreglado. Para ello contratan a un jardinero, un hombre un tanto extraño. La cena concluye y ya entrada la madrugada, el personaje-narrador escucha unos ruidos en el jardín. Es el jardinero que continúa su labor. Desconcertado, el personaje-narrador le indica que debe abandonar la casa. Al día siguiente, en el desayuno, le comenta a su mujer y a su padre lo sucedido y ellos le cuentan que el jardinero ha regresado. El padre justifica la actitud del jardinero: "es por las flores nocturnas". En este punto no sabemos a qué se refiere el padre, pero se deja entrever que emerge un elemento extraño en el orden natural de las cosas. Al final del relato, el personaje-narrador puede ver las flores nocturnas, pero no tiene forma de darles un sentido.

La pérdida de sentido se observa en el narrador que tiene dinero, pero en ningún momento se hace referencia a una pasión o vocación o a un trabajo (no 
se sabe cómo ha obtenido su dinero). Asimismo, se siente diferente a su padre porque no entiende la pasión de horas y horas.

De este modo, entra en crisis porque pierde el sentido de la vida. En "Flores nocturnas" el personaje, al igual que el lector, no accede a un sentido unívoco. Las flores nocturnas son un símbolo de una realidad perturbadora.

Esta crisis de sentido se puede advertir en el juego que se plantea a nivel de a anécdota. Frente al lector se abren distintas posibilidades:

¿Es la
revelado?

¿Es la historia de la nueva condición de rico del personaje y su origen no

¿Es la historia de la relación con su padre?

¿Es la historia de un encuentro con un jardinero extraño?

¿Es la historia de su acercamiento al misterio de la vida a través de las flores nocturnas?

En relación a lo que llamo misterio de la vida, Giddens señala: "Ser una persona es conocer, prácticamente siempre, mediante algún tipo de descripción o de alguna otra manera, tanto lo que uno hace como el por qué lo hace" (Giddens, p.51). Pero el personaje de "Flores nocturnas" no posee respuestas a cuestiones existenciales trascendentes. Lo que se observa, en cambio, es la falta de sentido: el hecho de no saber quiénes son se simboliza en las flores. Me refiero a que la crisis identidad es una crisis ontológica: no se sabe qué es el mundo, hay un misterio que horada la existencia humana.

\section{Texto, lenguaje y realidad}

Tanto el formato en que se desarrollan mis relatos como el tipo de personaje que se representa me lleva a la necesidad de plantear una visión de la realidad a partir de la noción de lenguaje con que opera Flores nocturnas. El lenguaje que subyace en Flores nocturnas plantea una desconfianza a su capacidad de representación y de recreación de la realidad, de tal modo que lo acerca al concepto de posmodernidad.

Lyotard, a partir de las formulaciones de lo sublime de Kant, ha planteado que existe una contradicción o conflicto entre la facultad de concebir una cosa y la facultad de presentar una cosa, pero en este libre acuerdo de facultades (nosotros diríamos arbitrario) proviene el sentimiento de lo bello. Sin embargo, en la vanguardia existe la consciencia de que la presentación muchas veces se torna insuficiente, las ideas no tienen presentación/representación posible, es más, son ideas que no nos dan a conocer nada de la realidad: son impresentables. El 
arte moderno, dice Lyotard, presenta lo que es impresentable, algo que es posible de concebirse, pero que no se puede ver ni hacer ver. (Lyotard, pp. 21-22)

Pienso, que estas conclusiones planteadas por Lyotard son interesantes y que evidencian que los vanguardistas y modernos en general tenían una confianza enorme en las posibilidades del lenguaje y su representación, aun cuando se presenta lo que es impresentable. En cambio, lo posmoderno expresa un giro en este problema de representación y realidad, es "aquello que indaga por presentaciones nuevas, no para gozar de ellas sino para hacer sentir mejor que hay algo de impresentable" (Lyotard, p.25).

En mis relatos, creo que hay algo que no se puede representar y el lenguaje es insuficiente. No es lo impresentable lo que se representa, no es la insuficiencia del lenguaje lo que se desliza en el discurso, la insuficiencia se vuelve parte de la representación, el vacío, lo inaprehensible.

\section{Las ideas actuales del cuento son viejas ideas}

Tanto en pintura como en música y literatura, tantas veces lo que llaman abstracto me parece apenas lo figurativo de una realidad más delicada y más difícil, menos visible al ojo desnudo

Clarice Lispector

Los cuentistas (los cuentistas de esta tradición chejoviana, que tiende a excluir lo fantástico y la fábula) sienten una especie de obsesión infantil por ese momento de revelación en que sus personajes comprenden o dejan de comprender algo esencial, ese momento en que la vida de un hombre cambia para siempre.

Juan Gabriel Vásquez

Las citas anteriores apuntan a la idea que está detrás de un cuento epifánico. Para un escritor contemporáneo como el colombiano Juan Gabriel Vásquez, el cuento chejoviano (epifánico) nos lleva hacia la comprensión de algo esencial. Esta noción de que podemos a través del arte acceder a una realidad desconocida hasta entonces está presente en las ideas estéticas desde el romanticismo, es decir son condiciones de la comprensión del arte que acompaña a escritores, críticos y lectores desde el comienzo mismo de la modernidad. Esta noción es mucho más evidente en Clarice Lispector. El arte nos acerca a una realidad "menos visible al ojo desnudo", pero que está allí, detrás de esa gran puerta que es la obra de arte.

Estas nociones, sin embargo, no serían posibles sin la estética. Como señala Boris Groys, los artistas necesitan de la teoría "para explicar lo que están haciendo, no a los otros, sino a sí mismos” (p. 34), precisamente porque la teoría 
crítica moderna y contemporánea "no es otra cosa que una crítica a la razón, a la racionalidad y a la lógica tradicional” (Groys, p. 36).

Pero hay que indicar que este "ayuda" de la estética no ha tenido un camino 1lano. Como señala Menke, la reflexión moderna sobre la experiencia estética está determinada por una ambivalencia no resuelta entre dos tradiciones: "La primera ve en la experiencia estética uno de los diferentes modos de experiencia y de discurso que constituyen la razón moderna, mientras que la segunda le atribuye un potencial que transgrede la racionalidad de los otros tipos no estéticos del discurso." (Menke, p.13) El primer modelo está articulado específicamente al concepto de autonomía, el segundo modelo al concepto de soberanía.

Este rasgo de soberanía en el arte es el que me interesa aquí, pues se enlaza con la idea del arte (y de las posibilidades del lenguaje artístico). El concepto de soberanía se asocia con la idea de que el absoluto está presente en la obra de arte. Así, para Adorno, el hecho estético "es soberano en la medida en la que no se inscribe simplemente en el tejido diferenciado de la razón plural, sino que lo transgrede." (Menke, p.14)

Según Menke, la experiencia estética tendría un potencial crítico capaz de cuestionar el predominio de la razón, lo que sería una exigencia idealista de verdad que es imposible de realizar en el dominio o ámbito extraestético (digamos, en el dominio de la vida social) y por lo tanto solo puede ser proyectada en la experiencia estética. Precisamente, este potencial crítico se observa en Flores nocturnas, pues en tanto tributario del cuento epifánico, el sentido oculto transgrede el predomino de la razón instrumental moderna.

\section{Referencias}

Baldeshiwiler, E. (1993) El cuento lírico: esquema para una historia. Del cuento y sus alrededores. Concepción y desarrollo del cuento moderno. Caracas: Monte Âvila Editores, 167-168.

Barrera, G. L. (1993). Aproximación a supuestos teóricos para un concepto del cuento. Del cuento y sus alrededores. Concepción y desarrollo del cuento moderno. Caracas: Monte Ávila Editores, 43-54

Díaz, W. (2006). El cuento epifánico. Técnicas del cuento, vol. II. Arequipa: Ediciones Apóstrofe, 108-120.

De Piérola, J. Final de juego. http://bitacora.josedepierola.com/?p=445

Eagleton, T. (2006). La estética como ideologia. Madrid: Editorial Trotta.

Foster, H. (2001). El retorno de lo real. Madrid: Akal ediciones.

Giddens, A. (2000). Modernidad e identidad del yo. Barcelona. Ediciones Península. 
Groys, B. (2016). Arte en flujo. Buenos Aires: Caja negra editora.

Huamán, M. A. (2005). Lecturas de teoría literaria II. Lima: Universidad Nacional Mayor de San Marcos.

Lispector, C. (1996) La explicación que no explica. Lauro Zavala (Editora). Poéticas de la brevedad. Teorías del cuento III. México: Coordinación de Difusión cultura UNAM, 193-212.

Lyotard, J-F. (1995). La posmodernidad (explicada a los niños). Barcelona: Editorial Gedisa.

Maffesoli, M. (2004) Yo es otro. Daza Navarrete, Gisela; Laverde Toscano, María Cristina y Zuleta Pardo, Mónica (editoras). Debates sobre el sujeto. Bogotá: Fundación Universidad Central. Siglo del hombre editores.

Menke, C. (1997). La soberanía del arte. La experiencia estética según Adorno y Derrida. Madrid: Visor.

Pacheco, C. (1993) Criterios para una conceptualización del cuento. Del cuento y sus alrededores. Concepción y desarrollo del cuento moderno. Caracas: Monte Ávila Editores, 11-42

Rest, J. (1971). El desarrollo del cuento. Buenos Aires: Centro Editor de América Latina

Touraine, A. (1994). Crítica de la modernidad. Buenos Aires: Fondo de Cultura Económica de Argentina.

Vásquez, J. G. (2008) Apología de las tortugas. http://elcuadernodesamuel.blogspot. pe/2008/07/apologa-de-las-tortugas.html 